\title{
Sustainable building design in Australia
}

\author{
C. McCabe \\ Cundall, Melbourne, Australia
}

\begin{abstract}
The building and construction industry in Australia has taken significant steps forward in the last 3-5 years to improve their environmental performance. This improvement has been in response to increased focus of local/state government policies regarding Ecological Sustainable Development (ESD), as well as the availability of holistic environmental rating tools such as the Green Building Council of Australia's Green Star rating tools.

However the unique climatic conditions of Australia, which range from hot arid to cool temperate combined with its expansiveness generate considerable challenges to building designers in achieving environmentally responsive and sustainable buildings.

In addition, designers are increasingly being engaged to contractually meet minimum environmental performance requirements that extend beyond energy conservation/greenhouse performance to cover issues such as water conservation, environmentally credible material selection, indoor environmental quality, transport, ecology and pollution as well as on-going environmental management of facilities.

This paper will provide an overview through the combined use of case studies of how designers in Australia are innovatively tackling the demand and contractual requirement for environmentally responsive buildings.
\end{abstract}

Keywords: climate, environmentally responsive buildings, ESD, Australia, environmental design.

\section{Introduction}

The adoption and integration of sound ESD design principles within the Australian construction industry has taken considerable steps forward in the last three to five years. The historic lip service approach to ESD is being steadily 
overtaken by an emphasis on accountability of a building's environmental performance.

This change in attitude has come from a number of directions including the combined drive from local and state government to embrace ESD, as well as the advent of a number of environmental assessment methods which are gaining acceptable within the construction industry.

To provide context to the case studies and examples outlined, a brief overview is provided into the design considerations of climate, rating systems and regulatory requirements that building designers are being challenged with to achieve successful environmentally responsive building design outcomes.

\section{Understanding the climate of Australia}

Climatic conditions in Australia vary considerably and offer significantly different opportunities and constraints in respect to the design of environmentally responsive buildings. Each state offers quite different climatic conditions and seasonal variations that the building designer must respond in order to ensure year round environmental responsiveness and comfort.

To assist designers, and in particular allow for energy benchmarking of different building classifications (residential; aged care; office or laboratory or clinic; shop or shopping centre; theatre or cinema; and school), the Building Code of Australia (BCA), the governing national regulatory body, has broken Australia down into eight different climate zones. The eight climate zones range from Zone 1, which reflects a high humidity summer and warm winter, through to Zone 8, alpine. The basis of these zones is shown in table 1 [1]:

Table 1: $\quad$ Table 1: Basis for BCA energy efficiency climate zones.

\begin{tabular}{|l|l|l|l|l|l|}
\hline $\begin{array}{l}\text { Climate } \\
\text { Zones }\end{array}$ & Description & $\begin{array}{l}\text { Average 3 pm } \\
\text { January } \begin{array}{l}\text { Average January } \\
\text { vapour pressure }\end{array}\end{array}$ & $\begin{array}{l}\text { Average } \\
\text { maximum } \\
\text { temperature }\end{array}$ & $\begin{array}{l}\text { July } \\
\text { temperature }\end{array}$ & $\begin{array}{l}\text { Average annual } \\
\text { Heating degree } \\
\text { days }\end{array}$ \\
\hline 1 & High humidity summer, warm winter & $\geq 2.1 \mathrm{kPa}$ & $\geq 30^{\circ} \mathrm{C}$ & - & - \\
\hline 2 & Warm humid summer, mild winter & $\geq 2.1 \mathrm{kPa}$ & $<30^{\circ} \mathrm{C}$ & - & - \\
\hline 3 & Hot dry summer, warm winter & $<2.1 \mathrm{kPa}$ & $\geq 30^{\circ} \mathrm{C}$ & $\geq 14^{\circ} \mathrm{C}$ & - \\
\hline 4 & Hot dry summer, cool winter & $<2.1 \mathrm{kPa}$ & $\geq 30^{\circ} \mathrm{C}$ & $<14^{\circ} \mathrm{C}$ & - \\
\hline 5 & Warm temperate & $<2.1 \mathrm{kPa}$ & $<30^{\circ} \mathrm{C}$ & - & $<1,000$ \\
\hline 6 & Mild temperate & $<2.1 \mathrm{kPa}$ & $<30^{\circ} \mathrm{C}$ & - & 1,000 to 1,999 \\
\hline 7 & Cool temperate & $<2.1 \mathrm{kPa}$ & $<30^{\circ} \mathrm{C}$ & - & 2,000 to Alpine \\
\hline 8 & BCA Alpine areas & &
\end{tabular}

The extent of each climate zone is visually depicted in the figure 1 [1].

While these do assist building designers to understand the prevailing climate of particular locations, the boundary lines between the climate zones has had to be simplified by aligning boundaries between zones with local government areas to ease administration. This simplification however does lead to some discrepancies with certain locations being linked to an unrepresentative climate zone for its prevailing climate. 


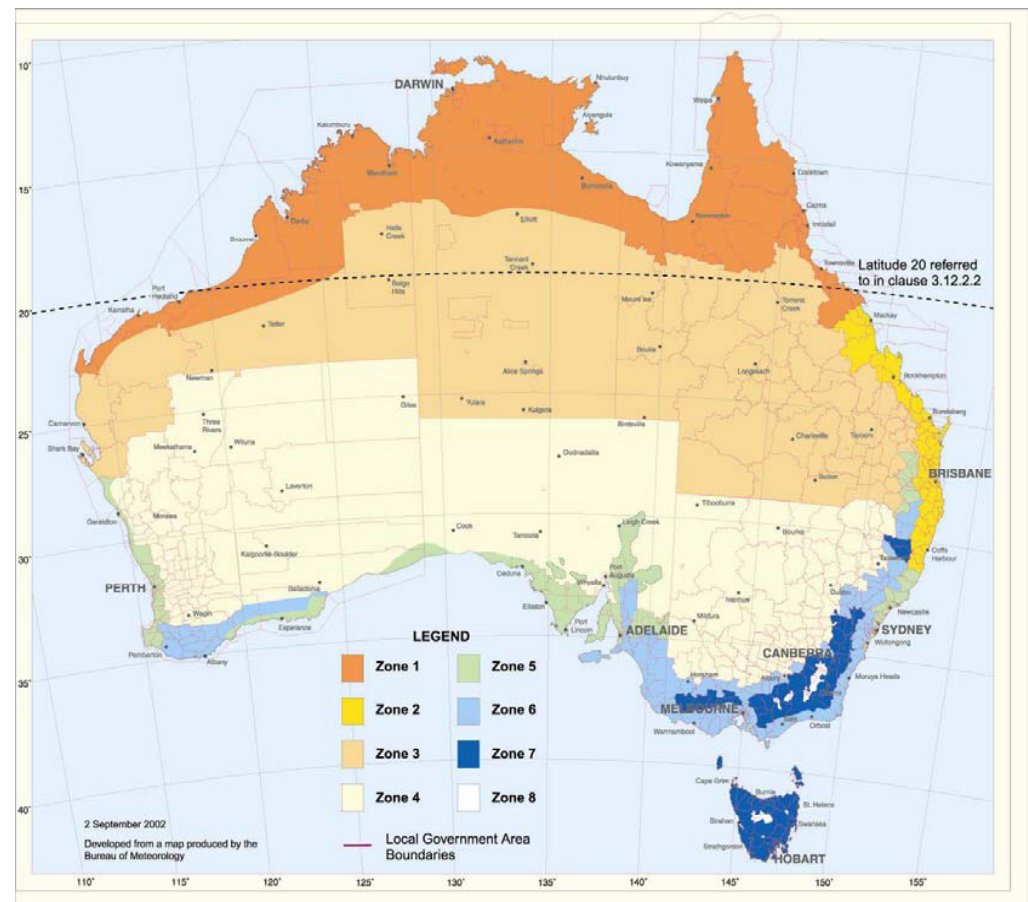

Figure 1: Climate zones for thermal design.

Therefore, while the BCA climate zones provides a rough guide to a locations prevailing climate, building designers require a more detailed understanding to enable full advantage of a locations prevailing climate to be captured in a buildings design response. However, to do so more representative climate must be found.

Unfortunately there are limited locations in Australia where hourly weather data (i.e. Test Reference Year (TRY) weather data) for use in performance assessment (i.e. computer simulation) of active and passive solar energy systems, annual energy consumption and indoor climate calculations. For example the two most populous states of Victoria and New South Wales covers $1,028,058 \mathrm{~km}^{2}$ have only 17 sites, most of which are in the city of Melbourne and Sydney. Less populous states and territories have even less, with the Northern Territory having only 3 sites to cover 1,349,129 $\mathrm{km}^{2}$.

In consideration of this designers must determine the most representative TRY weather site for locations outside of these limited locations having full 24 hour weather data. One approach is to compare the climates averages (i.e. temperature, humidity, rainfall, sunshine hours, wind speed and direction) of possible representative TRY weather sites with the desired location without full hourly weather data [3]. 
An example of one such comparison to determine the most representative or best fit site with full 24 hour data for a regional site of Ellinbank which has only $9 \mathrm{am}$ and $3 \mathrm{pm}$ weather data available, is shown in figure 2.

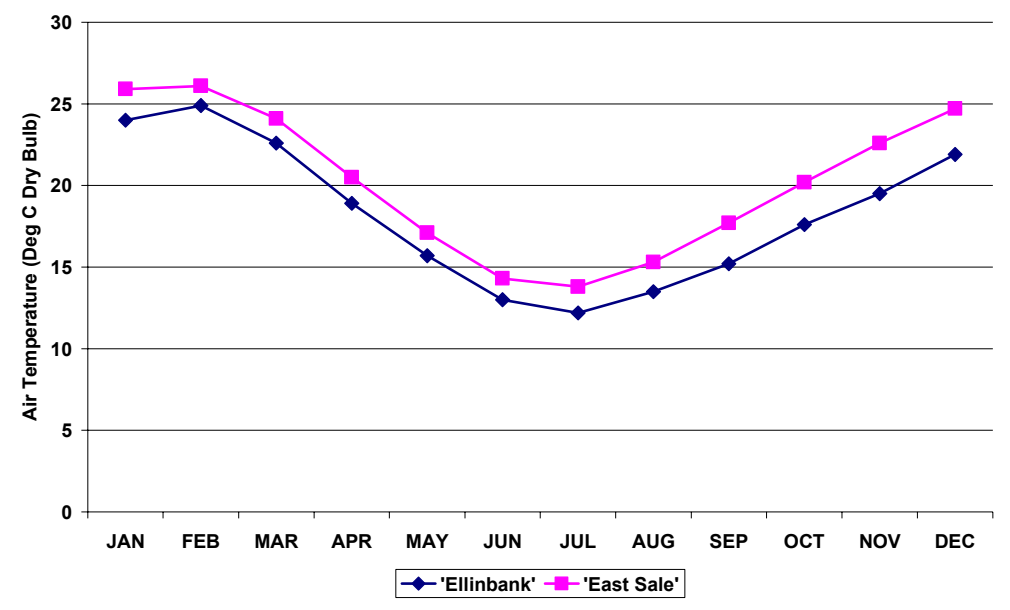

Figure 2: $\quad$ Mean daily maximum comparison between Alice Springs (Climate Zone 3), Mount Isa (Climate Zone 3) and Charleville (Climate Zone 4).

Another important consideration is to obtain local knowledge as it can be both useful and sometimes essential. For example Melbourne although considered to have a 'Mild Temperate' prevailing climate typically experiences two weeks in summer where air temperatures are the high 30's and it is not uncommon for it to reach $42-44^{\circ} \mathrm{C}$.

Using the same means of comparison but re-ordering summer and winter months to that of the northern hemisphere, it was interesting to note that the climate of Seville [4] Spain is similar to that of Cashmere Downs - Western Australia and the climate of Coruna [4] Spain is similar to that of Warrnambool Victoria. Thus suggesting that similar building design strategies used to maximise environmental performance could be applied in either location.

\section{Regulatory requirements}

\subsection{Building Code of Australia (BCA)}

The BCA [5] is a uniform set of technical provisions for the design and construction of buildings and other structures throughout Australia, which allows for variations in climate and geological or geographic conditions. The goals of the BCA are to enable the achievement and maintenance of acceptable standards of structural sufficiency, safety (including safety from fire), health and amenity for the benefit of the community now and in the future. 
The code goes through regular review introducing amendments and improvements following agreement between the Australian Government and each State and Territory Government. One such amendment is the introduction of minimum energy efficiency requirements and targets for residential development including with the aim of reducing greenhouse gas emissions by efficiently using energy, which comes into effect May 2005.

Similar energy efficiency requirements and energy performance targets are scheduled to come into effect May 2006 for the other Class of Building (aged care facilities, offices, laboratories, clinics, shops or shopping centres café or restaurants, theatres or cinemas and schools).

\subsection{Melbourne Docklands ESD Guide}

As part of the Melbourne Docklands commitment to and recognition of its role in the development of it has developed an Ecological Sustainable Development (ESD) Guide [6] which sets a minimum ESD performance for development approval while encouraging endeavour towards world's best practice. The purpose of the ESD guide is to inform all stakeholders about the principles and practices that currently guide the approach to ESD in Melbourne Docklands, as well as outline current environmental policies, plans and systems and explain the performance indicators that will be used to assess the relative ESD design performance for each building in the Docklands.

The performance indicators attribute points in respect to different areas based on the developments ESD design response. The ESD design elements covering Outdoor Space, the Site; Atmosphere; Water Cycle and Wastewater; Transport; Energy; Building Materials; Indoor Environmental Quality; Waste; and Innovation.

Depending on the developments score, a performance level is achieved from ESD Certificate of Achievement, ESD Award of Merit or a ESD Award of Excellence. The guide covers both residential and commercial development within the docklands and the performance rating of each building is primarily by self assessment with submission to the Docklands Authority for approval. The ESD design response is independently reviewed at each design against the Docklands ESD Guide Performance Indicators. The process is proving to be a success as it is rigorously enforced with all designs being audited at each design stage, resulting in both improved awareness within the development community and design professionals as well as credible and tangible ESD outcomes.

\section{Industry and national rating systems}

Over recent years there has been considerable expansion in the number of energy, greenhouse and environmental assessment tools being applied within the marketplace. Some are used to achieve market recognition others are used by government and planning authorities to stipulate minimum energy and environmental performance requirements. 


\subsection{National House Energy Rating Software (NatHERS)}

The NatHERS [7] software was developed by CSIRO on behalf of the Australian and New Zealand governments to provide a simulation tool for assessing the energy requirement in houses and apartments. The NatHERS ratings being used to both assist designers to improve a dwellings energy performance and provide a mechanism to set minimum energy performance requirements.

The software assesses the energy requirement $\left(\mathrm{MJ} / \mathrm{m}^{2} / \mathrm{a}\right)$ of a dwelling based on the passive solar / thermal design of the building fabric and orientation. The resulting performance is then rated from zero to five stars. The software has led to the evolution of accredited state specific assessment tools such as FirstRate in Victoria and is currently going through an evolution phase with a new national software called AccuRate expected later this year.

\subsection{Green Building Council of Australia's Green Star rating systems}

The Green Star [8] rating systems are a voluntary environmental rating system that provides an appraisal of a building overall environmental performance. The building is assessed under the categories of Management, Energy Use, Health and Well-being, Pollution, Transport, Land Use, Ecology, Materials and Water, to calculate its overall weighted score, which then determines its respective star or performance rating. Current rating tools evaluate new, refurbished and existing office designs with further rating tools under development for other building types such as residential, retail, assembly spaces and industrial buildings.

The Green Building Council's objective is to promote sustainable development and the transition of the property industry to implementing green building programs, technologies, design practice and operations. Although only in its second year the Star Rating systems are being embraced by industry and are being used to provide market differential to developers and building owners.

\subsection{Australian Building Greenhouse Rating (ABGR) scheme}

The Australian Building Greenhouse Rating (ABGR) scheme [9] provides an accredited means of benchmarking an office buildings greenhouse performance. It is a voluntary program for office buildings, designed to enable Base Building (central services), a Tenancy or for the Whole Building performance to be assessed. Providing building owners, managers and tenants to get market recognition for superior greenhouse performance and identify ways in which greenhouse performance can be improved.

Ratings can be carried out for existing office buildings based on actual metered energy consumption and new buildings based on energy consumption determined using their validation protocol for computer simulations. The respective greenhouse performance of an office is rated from one to five stars in incremental and $1 / 2$ star steps. With a 1 -Star reflecting a building with poor energy management or outdated systems, though to a 5-Star which represents a 
building that is as good as it gets, due to its integrated design, operation, management and fuel choice.

\section{Case studies and examples}

The following provides a brief introduction and overview of a selection of case studies which provides insight into sustainable buildings are being delivered in Australia, which will be expanded and elaborated on in the formal presentation.

\subsection{The Bond, Bovis Lend Lease headquarters}

Recently completed headquarters for Bovis Lend Lease, which took a strong and integrated environmentally focused approach to its design. The building comprises approximately $18,700 \mathrm{~m}^{2}$ of office space, a $600 \mathrm{~m}^{2}$ communal atrium and basement parking for 113 cars.

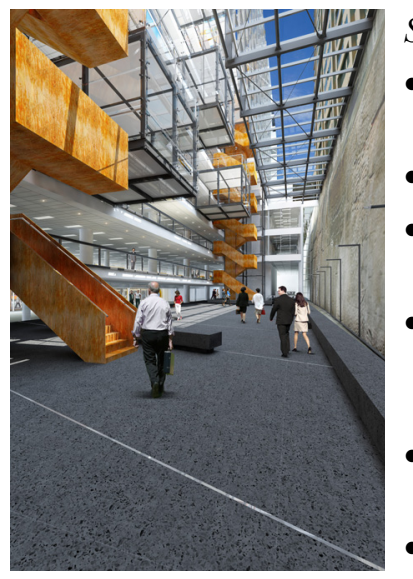

\section{Selected Sustainable Design Features}

- Australia's first predicted 5-star ABGR greenhouse performance rated office building.

- 5-Star Green Star pilot rated design.

- First large scale use of active chilled beams in an office development.

- Operable external shading on western façade that deploys progressively during the day to maximise views and minimise solar heat penetration.

- Maximised useful penetration of daylight into the building via the perimeter and atrium.

- Distributed naturally ventilated sunrooms on each floor taking advantage of Sydney's climate.

Figure 3: $\quad 30$ The Bond, Bovis Lend Lease headquarters.

\subsection{Modernisation of DNRE Regional Institutes}

Modernisation of the Department of Natural Resources and Environment Dairy Research Institute at Ellinbank, Regional Offices at Horsham and Regional Tatura Offices. The integration of environmentally responsive design principles was a key requirement and client objective for each project and led to highly innovative design solutions. Independent review of the environmental design solutions, were also a key client driven requirement of the project.

\subsection{Monash Science Centre}

The new Monash Science Centre will serve as common ground to bring research scientists and primary / secondary students as well as the general public together, 
encouraging their interaction and promoting an exchange of ideas and information. Sited on a green field site, the building comprises of two main pods: a classroom wing and exhibition hall.

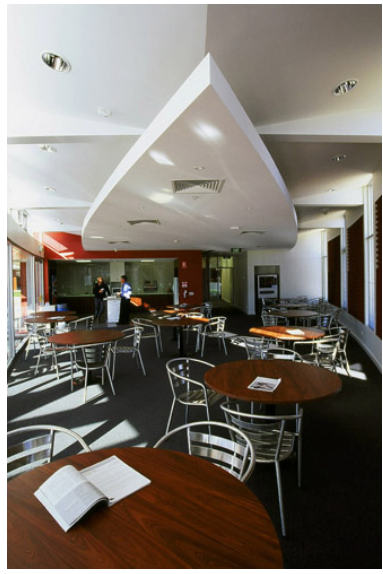

Selected Sustainable Design Features

- Non-refrigerative air conditioning through the combination of a thermal labyrinth and creek water storage system in Ellinbank.

- Thermal labyrinth to pre-condition incoming outside air for Link Building at Horsham.

- Particularly strong emphasis on water conservation, rainwater harvesting for re-use and process water collection, treatment and re-use.

- Integration of free daylighting, natural ventilation, night-purge strategies.

Figure 4: $\quad$ Modernisation of DNRE Regional Institutes.

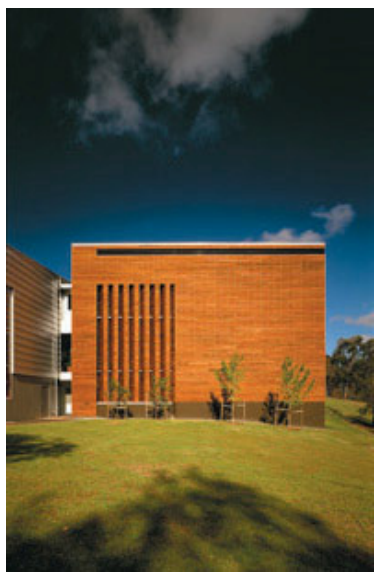

\section{Sustainable Design Features}

- Hydronic underfloor heating is used throughout, below the timber floor for winter comfort control.

- Heating requirements provided by a geothermal field within an adjacent permanent retard basin.

- Summertime comfort control in the exhibition hall is achieved through combined cross flow ventilation / stack ventilation and both single and cross ventilation in the classrooms.

- Diffuse daylight throughout classrooms via carefully configured glazing and light shelves.

- Environmentally credible material selections.

Figure 5: $\quad$ Monash Science Centre.

\section{Conclusions}

Australia has taken considerable steps forward from an ESD perspective, achieved through the combined push for the introduction of regulatory requirements and targets, as well as the recent presence of independent greenhouse and environmental rating tools. Increasingly ESD is becoming an inherent consideration in the design of buildings. The construction industry is 
being challenged to take an integrated design approach and to date is striving to meet this challenge.

Although the climatic conditions in Australia vary considerably from State to State requiring different design approaches and solutions, there is considerable potential within Australia to take advantage of its climate to achieve strong environmentally responsive outcome. However, considering the strong similarities between the climate of Australia and Spain, it would have been interesting from a building design perspective if it had been colonised by a more Southern European country such as Spain.

\section{References}

[1] Energy Efficiency BCA 2005 Volume One - Regulation Document, Proposal for Class 5-9 Buildings, RD 2004-01, November 2004, p 5.

[2] BCA 2005 Volume One - Class 2 to Class 9 Buildings, pp 22 - 24.

[3] Australian Government, Bureau of Meteorology, website, www.bom.gov.au.

[4] Spanish Weather Data, website, www.bbc.co.uk/weather/world/ city guides.

[5] Building Code of Australia (BCA) 2005 Volume One and Volume Two

[6] Melbourne Docklands, ESD Guide, downloadable from www.docklands.com/docklands/about/publications/esd/index.shtml.

[7] National House Energy Rating Scheme (NatHERS), www.energysmart. com.au/les/Displaypage. asp?flash=-1\&t=2005453\&PageID=309.

[8] Green Building Council of Australia (GBCA), Green Star rating systems downloadable from www.gbcaus.org/greenstar.

[9] Australian Building Greenhouse Rating (ABGR) Scheme, website www.abgr.com.au. 